\title{
Evidence based pathways to intervention for children with
}

\section{Language Disorders}

\author{
*Ebbels, S.H; McCartney, E; Slonims, V; Dockrell, J.E; Norbury, C.F
}

*corresponding author. Contact: ebbelss@moorhouseschool.co.uk

This is the peer reviewed version of the following article: Ebbels, S. H., McCartney, E. , Slonims, V. , Dockrell, J. E. and Norbury, C. F. (2019), Evidencebased pathways to intervention for children with language disorders. International Journal of Language \& Communication Disorders, 54: 3-19, which has been published in final form at https://doi.org/10.1111/1460-6984.12387. This article may be used for non-commercial purposes in accordance With Wiley Terms and Conditions for self-archiving. 


\section{Abstract}

Background: Paediatric SLT roles often involve planning individualised intervention for specific children, working collaboratively with families and education staff, providing advice, training and coaching and raising awareness. A tiered approach to service delivery is currently recommended, whereby services become increasingly specialised and individualised for children with greater needs.

Aims: To stimulate discussion regarding delivery of SLT services by examining evidence regarding the effectiveness of 1 ) intervention for children with language disorders at different tiers and 2) SLT roles within these tiers; and to propose an evidence-based model of SLT service delivery and a flowchart to aid clinical decision-making.

Methods: Meta-analyses and systematic reviews, together with controlled, peer-reviewed group studies where recent systematic reviews were not available, of interventions for children with language disorders are discussed, alongside the differing roles SLTs play in these interventions. Gaps in the evidence base are highlighted.

Main Contribution: The service delivery model presented resembles the tiered model commonly used in education services, but divides individualised (Tier 3) services into Tier 3A: indirect intervention delivered by non-SLTs, and Tier 3B: direct intervention by an SLT. We report evidence for intervention effectiveness, which children might best be served by each tier, the role SLTs could take within each tier, and the effectiveness of these roles. Regarding universal interventions provided to all children (Tier 1) and those targeted at children with language weaknesses or vulnerabilities (Tier 2), there is growing evidence that approaches led by education services can be effective when staff are highly trained and well-supported. There is currently limited evidence regarding additional benefit of SLT-specific roles at Tiers 1 and 2. With regard to individualised intervention (Tier 3), children with complex or pervasive language disorders can progress following direct individualised intervention (Tier 3B), whereas children with milder or less pervasive difficulties can make progress when intervention is 
managed by an SLT, but delivered indirectly by others (Tier 3A), provided they are well-trained, supported and -monitored.

Conclusions: SLTs have a contribution to make at all tiers, but where prioritisation for clinical services is a necessity, we need to establish the relative benefits and cost-effectiveness at each tier. Good evidence exists for SLTs delivering direct individualised intervention and we should ensure that this is available to children with pervasive and/or complex language disorders. In cases where service models are being provided which lack evidence, we strongly recommend that SLTs investigate the effectiveness of their approaches. 


\section{What this paper adds}

What is already known on this subject. A tiered approach to service delivery is often recommended, in which intervention for children with language disorders becomes increasingly individualised. A current dilemma is how to balance time spent supporting and training other professionals who can reach a greater number of children against the provision of individualised intervention for a smaller number of children with the most severe language disorders, in the context of limited resources.

What this study adds. We aim to stimulate discussion by highlighting available evidence regarding the effectiveness of intervention and SLT roles at different tiers. We provide a model that is based on this evidence and that 1) describes the children who may best be served by each type of input and 2) illustrates what form SLT input could take at different tiers. We also provide a flowchart to aid clinical decision making.

Clinical implications. Our evidence review indicates that SLTs must ensure sufficient training and skills in others asked to deliver language interventions. Furthermore, education staff and families may require on-going support to enable them to deliver evidence-based programmes as intended. Children with complex and pervasive language impairments have distinct needs and are likely to require individualised SLT support which includes close collaborative working between SLTs, education staff and families, and in some cases direct SLT intervention. Thus, service delivery models should ensure SLTs have sufficient time to work effectively with these children. 
Speech and Language Therapists (SLTs) are an integral part of the children's workforce. They contribute specialist knowledge and skills regarding children's speech, language, and communication development and work alongside other professionals to enhance communication, especially in children with difficulties in these areas. There have been recent changes in the roles and locations in which paediatric SLTs work and many are now based in the community and in schools. Indeed many are now employed directly by schools. Roles may be determined or facilitated by the model of employment and whilst a move away from the clinic into educational provision and the community is positive, leading to increased collaborative working in ecologically valid contexts, it has also led to an increasing focus on the language needs of all children, as opposed to only those with severe needs (Bercow, 2008). Without increased staffing levels, this may have resulted in decreased time for direct intervention (less than a quarter of the average SLT's time is spent on this (Pring et al., 2012)), and an accompanying dissatisfaction with service delivery models from some SLTs (Pring et al., 2012) and parents (Dockrell et al., 2006). Other parents are more positive, especially those whose children attend schools with specialist provision (Lindsay et al., 2016).

We aim in this paper to consider the effectiveness of different roles played by SLTs as part of an integrated workforce and to stimulate discussion about how best to provide services in an effective manner. Different models of employment of SLTs apply internationally and influence service delivery, practitioner roles and skills set. However, issues regarding prioritisation of unmet need are universal, so our discussion aims to be relevant to SLTS/SLPs internationally.

Recent models of SLT service delivery for children and young people conceptualise services as involving a hierarchy of SLT involvement, whereby some support is provided for all and greater support for those children with more severe needs (e.g., Gascoigne, 2006, Law et al., 2013). These models resemble those in education and youth justice services, variously called Tiers/Stages/Waves or Response to Intervention (RTI) models (e.g., Fuchs and Fuchs, 2006, Snow et al., 2015). However, there is a lack of clarity about the precise nature and aims of SLT roles at different tiers, and evidence that these roles are effective in achieving these aims is sparse. 
Our purpose here is first to present a modified version of a tiered intervention model, which splits Tier 3 in order to provide clarity regarding interventions at this tier. Then, we summarise for each tier the available evidence regarding the effectiveness of a) support and/or intervention for children at that tier and b) SLT roles within each tier. This paper is a discussion paper, not a systematic review. However, we draw on evidence from systematic reviews and meta-analyses where possible. Where these are not available or more recent studies are available, we include discussion of individual studies, although we do not include single case studies. Based on the evidence reviewed, we then suggest an overall model of SLT service delivery and a flowchart to aid clinical decision making.

We recognize that evidence is not the only influence on clinical decision making; evidence based practice involves using clinical expertise and experience to make decisions about the care of individual clients by integrating the values of the "fully informed" client with the best available evidence from systematic research into the decision making process. In addition, there are ethical, financial, national and local political considerations which influence service decisions. However, outcomes should inform the decision making process. By summarising the evidence we aim to a) help clinicians to present an overview of the evidence to clients, so they are "fully informed" and b) stimulate discussion about the direction of the profession in relation to children's SLT services, highlighting where further research is needed. An important premise is the general agreement that communication is a human right and that SLTs have a key role to play in maximising functional communication in children with speech, language and communication needs (see recent issue of International Journal of Speech Language Pathology, McLeod, 2018).

In this paper, we focus primarily on children with Language Disorder. Language Disorder arises in development and is affected by a complex interplay of genetic and environmental factors. We use the term Language Disorder in the manner set out in Bishop et al. (2017); to refer to all children with language difficulties that cause functional impairment in everyday life and are associated with poor prognosis. This includes children whose language difficulties occur in isolation (for which the recommended term is Developmental Language Disorder, or DLD) and those whose language difficulties 
are associated with other conditions such as autism. For brevity we have limited ourselves to literature relating to the populations which comprise a significant percentage of children's SLT services. We do also consider pre-school children with low language where the prognosis is unclear, who would often be served by Tier 1 and Tier 2 interventions. Both groups of children (those with language disorders and those with language difficulties with unclear prognosis) are included in the umbrella term Speech Language and Communication Needs (see RCSLT, 2017).

SLTs working with language difficulties or language disorder are part of the multi-disciplinary children's workforce who have complementary skills and a common goal of maximising the child's functioning, activity, well-being and participation, both in education and socially. The SLT's specific role in part depends on the roles and working models of the other professionals in that workforce. Close collaboration between SLTs, families and other professionals supporting children with language difficulties and disorders is a crucial component of effective support for these children and their families.

\section{Tiered intervention models}

Tiered intervention models generally divide intervention into three different levels, waves, stages or tiers (e.g., Fuchs and Fuchs, 2006, Gascoigne, 2006, Law et al., 2013, Snow et al., 2015). However, there is a mismatch in terminology used in education versus health services (shown schematically in Figure 1). 
Children

Intervention

Education tiers

SLT services
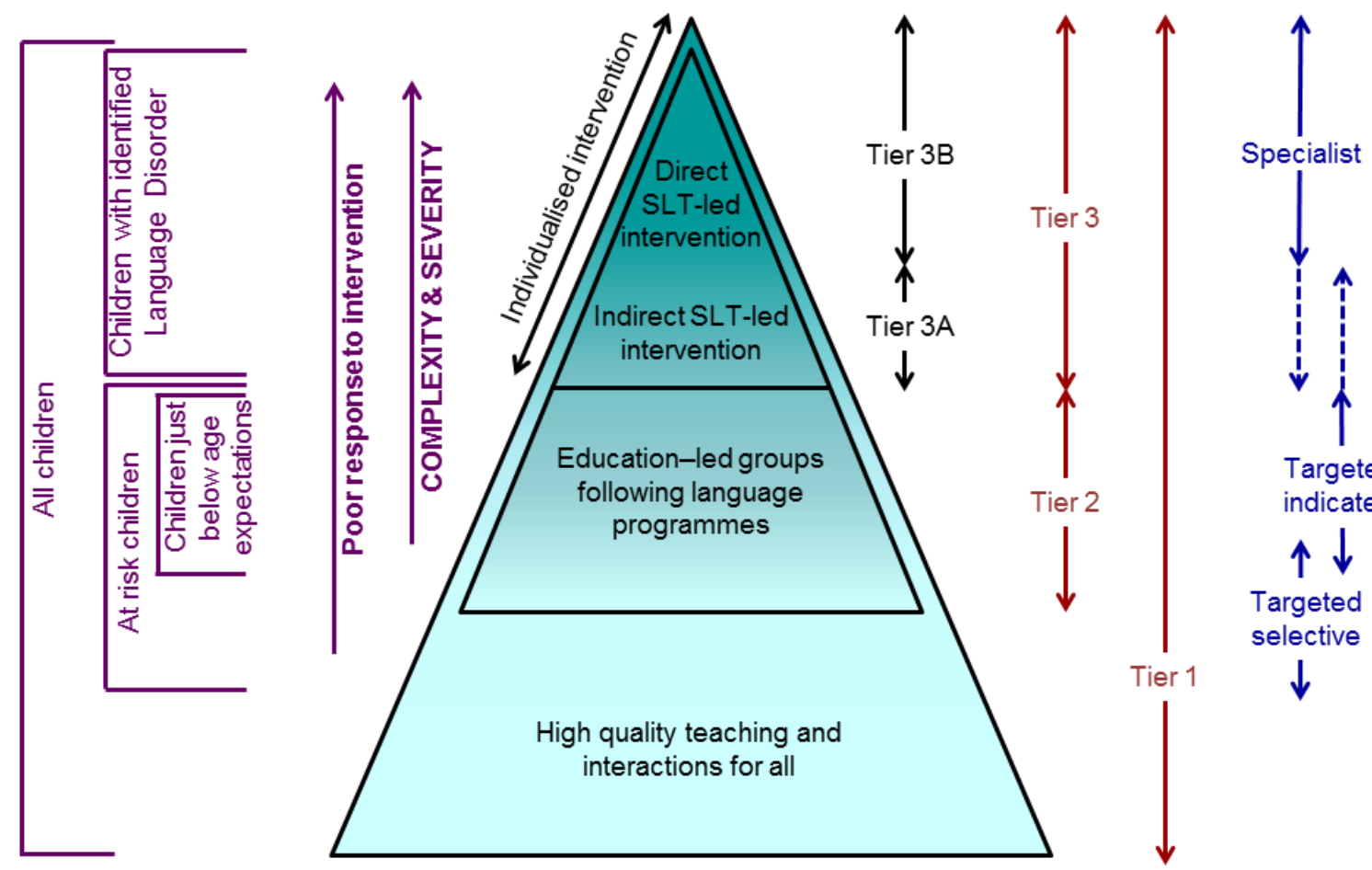

Targeted indicated

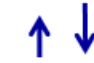

Targeted selective $\downarrow \quad$ Universal

Figure 1 - Response to intervention model of intervention for children with language disorders

Education intervention tiers are generally related to the characteristics of children. Tier 1 aims to provide high-quality teaching for all; Tier 2 provides education-led language programmes for children performing just below age expectations; and Tier 3 focuses on children with identified language disorders, who are not making expected progress and are likely to require individualised intervention. Tiers are thus broadly matched to interventions, but focus on child need (e.g., Fuchs and Fuchs, 2006). In contrast, "universal", "targeted" and "specialist" SLT services describe the type of support or intervention provided by SLTs or the aims of the intervention in terms of prevention (Law et al., 2013). "Specialist interventions" usually involve individualised intervention devised by an SLT for a specific child (which broadly aligns with education's Tier 3 ) and aim to improve skills, reduce the functional impact of the impairment and increase participation, potentially preventing negative secondary sequelae. The 
labels "targeted" and "specialist" are both used to describe intervention managed but not directly delivered by an SLT. This is confusing. For example, Scottish Government (2010) guidance reflects most allied health profession practice in stating that when an SLT has a duty of care and is managing intervention (regardless of whether the intervention is delivered 'directly' by an SLT or 'indirectly' by non-SLTs under the direction of the SLT), this is specialist intervention. However, some (e.g., Law et al., 2012, 2017) regard indirect intervention as "targeted" intervention because it is not delivered by a SLT, even though it is individualised to the child and overseen by an SLT. This lack of consistency is indicated in Figure 1 by the dashed arrows. To avoid confusion, we split Tier 3 into Tier 3B for direct individualised/specialist intervention and Tier 3A for indirect individualised intervention (currently called variously "specialist" or "targeted" - see Figure 1). We consider it essential to distinguish "indirect" work for which an SLT has a duty of care (which we call Tier $3 \mathrm{~A}$ ) from that delivered by education services at Tier 2, where the SLT does not have a duty of care, although the child may be recognised as having special educational or additional support needs.

The precise definition of "targeted intervention" is unclear in SLT practice, but the primary focus is on "vulnerable" children (Gascoigne, 2006) with the aim of decreasing the prevalence of language difficulties in the population (Law et al., 2013). The provision of small group work at Tier 2 for children who have been identified as having language levels below age expectations would fall under "targeted" interventions in most definitions. However, any lack of distinction between Tier 2 and what we call Tier $3 \mathrm{~A}$ is problematic if it is unclear whether or not an SLT has a legal and ethical responsibility for the intervention provided.

"Targeted" intervention can also, in most interpretations, cover interventions/advice for vulnerable groups of children who, due to family circumstances such as economic hardship, are deemed to be at increased risk of language difficulties. These children have not been identified as having language levels below age expectations and some may have language abilities within the expected range. This is sometimes referred to as "targeted selective" intervention, (as opposed to "targeted indicated" where the children's lower language levels are known, see above, Asmussen et al., 2016). In 
this paper, we will discuss studies under Tier 1 if they are designed to help all children, but under Tier 2 if they provide intervention for a limited number, often in small groups.

"Universal" SLT services aim to prevent future problems (Law et al., 2013), by providing effective, inclusive, communication environments for all. SLT roles in universal services often focus on two important areas: improving the ability of parents and professionals to identify speech, language and/or communication difficulties in children, and enhancing interaction to maximise opportunities for all children to develop good communication skills (thus aligning with Tier 1).

The lack of agreement in terminology hinders mutual understanding and effective collaboration between education and health services, and in practice intervention levels are not always clearly signalled (Law et al., 2012, p14), leading to confusion about where responsibilities for intervention lie. In this paper, we consider the evidence for effectiveness of interventions in terms of levels shown inside the triangle in Figure 1, mapped to education services' Tiers 1, 2 and 3 which we label:

1. High quality teaching and interactions for all children (Tier 1)

2. Education-led small groups following manualised language programmes (Tier 2)

3. Individualised intervention where children are registered on an SLT caseload and where the SLT has a duty of care (Tier 3). This is split into:

A. Tier 3A: Indirect individualised intervention planned and monitored by the SLT but delivered by parents or a member of the children's workforce.

B. Tier 3B: Direct individualised intervention, delivered by the SLT who planned the intervention.

Figure 1 shows lines between the tiers and for clarity we will discuss the evidence for each tier separately. However, both the interventions and children's needs are better viewed as a continuum.

\footnotetext{
Aims

For each tier, we first summarise the evidence for effectiveness of intervention for children with language difficulties and disorders, then consider the roles SLTs may play in the delivery of intervention, and summarise the available evidence regarding the effectiveness of these roles. In addition, we consider evidence of effectiveness of SLTs' joint collaborative work and training with
} 
parents and other professionals, across all tiers. Finally, we describe a model of service delivery based on the evidence reviewed.

\section{Method}

For each tier, we first searched for systematic reviews and meta-analyses published from year 2000 using the SpeechBite website (http://speechbite.com/), Cochrane database, and Google Scholar. Where several reviews or meta-analyses exist for a topic, we chose the most recent and the most relevant to the discussions in this paper (i.e., those focusing on service delivery rather than specific interventions). Where we found no recent systematic reviews or meta-analyses, we discuss older systematic reviews, more recent narrative reviews and individual papers published in the relevant area since the last review. We excluded single case studies and indicate whether other studies were randomised control trials (RCTs).

\section{Tier 1 interventions (high quality teaching and interactions for all children)}

\section{Evidence of effectiveness of Tier 1 interventions}

For children enrolled in education, effective Tier 1 provision requires active classroom management and teaching to support the development of oral language skills. Tier 1 intervention may involve teachers or early educators delivering language programmes to all children in their classes and large-scale cluster RCTs have shown these can result in improved performance in grammar, morphology and vocabulary (Neuman et al., 2011, Vadasy et al., 2015, Apthorp et al., 2012). However, a large Danish RCT providing a lower level of input (Bleses et al., 2017) did not result in significant changes in child language. The fact that the number of sessions delivered was a significant predictor suggests that better results may have been achieved with more intervention.

Tier 1 intervention may also involve professional development (PD) for education staff. Several large-scale RCTs in Canada and the United States have explored the effectiveness of PD for pre-school educators and a recent meta-analysis of studies of PD focusing on language and/or literacy (MarkussenBrown et al., 2017) found medium effects on adult-child interactions and large effects on the physical 
classroom space, but no significant effect on educator knowledge. Less than half of the included studies reported child outcomes, but the meta-analysis revealed a non-significant effect on child vocabulary and small to medium significant effects on phonological awareness and alphabet knowledge. Surprisingly, the improvements in child outcomes were not mediated by improvements in the way the adults interacted with the children. Markussen-Brown et al. (2017) found better outcomes for PD of longer duration and greater intensity (the average amount of PD was around 50-60 hours) and while courses alone had no significant effects, courses plus components such as coaching and feedback had significantly larger effects. The most important predictor was whether the PD included more than one component (e.g., course plus coaching and feedback, or the addition of a language curriculum or use of assessment data to guide lesson planning).

Fewer studies have been carried out considering the effects of PD for teachers in schools. Snow et al.'s (2014) cluster RCT involving fourteen primary schools in a socio-economically disadvantaged area found six days of PD plus follow-up support improved children's average oral language and literacy skills. It is not clear whether the changes applied to children with language disorders, as their results are not reported separately.

In a smaller study comparing two secondary schools, one intervention and one control (Starling et al., 2012), adolescents with language disorder were assessed following teacher training in language modification techniques ( 8 hours training plus observation and coaching). Results indicated positive changes in the adolescents' written expression and listening comprehension, but not reading or speaking. However, due to the design of this study it is possible that changes may have resulted from school differences rather than the intervention per se.

The above studies on PD for education professionals involved a high level of commitment from researchers and education staff. Courses alone do not appear to be effective unless combined with other components such as individual coaching and feedback, tailored to the needs of individual staff. 
Tier 1 services also focus on children before they enter education and often aim to change parents' interaction with their children, to increase the amount of contingent talk (McGillion et al., 2017, Landry et al., 2006) or increase the vocabulary children are exposed to, for example via interactive shared book reading (Mol et al., 2008). A meta-analysis of parenting education programs for children aged 3 to 5 years (Grindal et al., 2016) found little beneficial effect unless opportunities to practice parenting skills were provided. The addition of coaching and feedback led to larger effects. However, evidence from RCTs with parents of infants (below 1 year old) found training alone via a video focused on increasing contingent talk (where the caregiver talks about what is in the infant's current focus of attention, Landry et al., 2006, McGillion et al., 2017), can lead to positive effects on children's language. However, these may not be maintained in the longer-term (McGillion et al., 2017).

Meta-analyses of family-based emergent literacy interventions (Mol et al., 2008, Manz et al., 2010) found moderate effects on expressive language, and smaller effects on receptive language. However, the effectiveness was substantially reduced for "at risk" children in families with low incomes or less educated mothers. A similar result was found in a meta-analysis of vocabulary interventions for children aged 0-6 years (Marulis and Neuman, 2013); while these were generally effective, effect sizes were significantly lower in children from low SES backgrounds and were further reduced if children had additional risk factors. Thus, careful evaluation of Tier 1 interventions designed to enhance language in all children is needed to establish whether they are effective for children at highest risk for continuing language difficulties.

\section{SLT roles in Tier 1 interventions}

There has been little evaluation of the effectiveness of SLT-specific roles in universal health and education services for children. These Tier 1 roles usually focus on training others to promote the development of speech, language and communication. Law and Pagnamenta (2017) found that more than $50 \%$ of UK SLT services are working at Tier 1 with children aged 0-2 years, but it is unclear if training provides the $50-60$ hours in the studies discussed in the previous section. A recent scoping review (Smith et al., 2017) focused on SLT roles in health promotion for children aged 0-3 years concluded "the 
lack of quality in reporting and study design result in an inability to draw any conclusions regarding the effectiveness of speech and language therapy health-promotion services for early language delay".

Other SLT roles at Tier 1 focus on raising awareness in the general public (especially parents) and policymakers of 1 ) the importance of language to economic independence, health and well-being and 2) identification of children with language disorders and the 'red flags' and risk factors for a persistent language disorder (further discussed below). Public awareness raising is often the remit of membership organisations, professional bodies and charities. The effectiveness of SLTs in these activities should be measured against these other lobbying and public information activists. However, SLT services have a role in raising awareness among those who are potential referrers of important 'red flags' and risk factors for persistent language disorders.

Tier 1 intervention is often described as 'preventative,' (e.g., Law et al., 2013) but most models of education and SLT service delivery acknowledge that a number of children are likely to need more targeted or individualised support at Tiers 2 or 3 . Longitudinal studies of children with DLD indicate that difficulties persist well beyond the early years and may affect social and work contexts into adulthood and thus long-term support may be required.

\section{Tier $\mathbf{2}$ interventions (education-led small groups delivering language programmes)}

\section{Evidence of effectiveness of Tier 2 interventions}

A number of research studies have evaluated interventions delivered to support oral language skills in small groups of children with weaknesses or "vulnerabilities". Some studies could be described as "targeted selective" because recipients were in high-risk groups rather than being included based on their actual language abilities. For example, Dockrell et al. (2010) found improved receptive and expressive language performance following "Talking Time" groups with pre-school children from deprived areas learning English as an additional language. Other studies were RCTs involving children with identified language difficulties ("targeted indicated") with a focus on improving receptive and expressive language (e.g., Nuffield Language Programme, Bowyer-Crane et al., 2008, Fricke et al., 2013, 2017, Talk Boost, Lee and Pring, 2016) and vocabulary (Connections, Vadasy, 2015b). A pair of RCTs in 
the US evaluated Tier 2 interventions in a response to intervention model for children whose difficulties persisted following high quality Tier 1 intervention in pre-school settings (Lonigan and Phillips, 2016). In Study 1 , they found no benefit from the language intervention groups, but some benefit was evident in Study 2 after extensive modifications including reducing the group size from six to four, increasing training to twenty hours for the professionals delivering the intervention and reducing the number of intervention targets. However, the authors suggest that even more intervention than the 15 hours provided may be required.

The above interventions were typically carried out by education staff in schools, with researchers providing training and on-going support, and measuring fidelity of delivery of the intervention. Evidence is emerging that generalisation to regular practice in which training is not provided by the developer of the programme and is at lower intensities results in smaller effect sizes than the original studies (Fricke et al., 2017), and in some cases no significant effects (Thurston et al., 2016). Therefore more effectiveness trials of promising interventions are needed to establish the quantity and quality of training required for these programmes to be successfully delivered in schools without support from the original developers.

\section{SLT roles in Tier 2 interventions}

Whilst SLTs frequently present school staff with language and communication programmes, the majority of the studies discussed above were led by education or psychology researchers, and in the studies with large and significant effects, the originators of the intervention provided the training to those delivering it. Given the small effects in the RCTs by Fricke et al. (2017) and Thurston et al. (2016) when SLTs provided the training, indications are that training and support for such programmes needs to be at higher intensity than was provided in these studies, and the quality of training and coaching provided by SLTs needs to be evaluated.

\section{Tier 3 interventions (individualised intervention)}

Individualised interventions are based on assessment of a particular child's needs. In clinical practice, the recommendation is that the professional with a duty of care for the child should monitor the delivery and outcomes of each period of intervention. Planning will usually take into account the 
views of the child, family and education staff. When asking others to share the delivery of intervention, the SLT has a responsibility to provide the necessary training, support and resources to ensure a high quality intervention specifically tailored to the child's needs. In the UK, many SLTs use an "episodes of care" approach in which the SLT 'opens' or initiates an 'episode' of intervention and when this is completed they 'close' it, discharging the child from their care until any further re-referral. This contrasts with education provision which is on-going throughout the school years, and now (in the UK at least) potentially to 25 years (Department for Education and Department of Health, 2015). Whilst "episodes of care" allow a service to manage the demands of a large caseload of children, there is a risk of failure to assess the need for further provision for children after discharge. For example, in a study by McCartney and Muir (2016) SLTs reported that failure to understand the need for re-referral resulted in some school leavers with learning disabilities missing SLT assessment of post-school intervention needs. Thus, careful explanation and discussion with other professionals regarding re-referral processes, and the meaning of this form of case closure or 'discharge', is required.

In the next sections we split individualised intervention into direct intervention, delivered by the SLT (often with others supporting practice and the generalisation of new skills) versus indirect intervention, delivered by non-SLTs, such as parents or education staff.

\section{Direct individualised intervention (Tier 3B)}

For children with DLD (many of whom would previously have been diagnosed as having Specific Language Impairment, SLI), good evidence exists of positive effects of individualised 1:1 direct intervention with an SLT for improving expressive language skills and vocabulary (for reviews see Law et al., 2003, Ebbels, 2014, Lowe et al., in press) and some studies are beginning to emerge considering the effectiveness of delivery of intervention via telehealth (Wales et al., 2017). Fewer studies explore the effectiveness of intervention for children with severe and pervasive difficulties, including receptive language difficulties (see review by Boyle et al., 2010). In general, studies using standardised tests as outcome measures fail to show significant effects of intervention for children with receptive difficulties; see Boyle et al. (2009) and Gillam et al. (2008), both RCTs. These data raise the issue of the use of 
assessments in populations for whom they were not developed or for purposes for which they were not designed (Dockrell and Marshall, 2015). Standardised tests can be a measure of change for some children, e.g., they detected expressive language gains in Boyle et al. (2009)'s cohort, but they may not be sufficiently sensitive to smaller changes in children with severe and pervasive difficulties. Studies using more tailored measures of progress generally show larger effect sizes and indeed such studies have found significant gains with intervention targeting either a range of areas (Ebbels et al., 2017, Gallagher and Chiat, 2009) or the specific language areas of receptive vocabulary and word finding (Throneburg et al., 2000, Wright et al., in press, Ebbels et al., 2012, Hyde-Wright et al., 1993) and production and comprehension of specific grammatical structures (Ebbels et al., 2014, 2007). Note that Gallagher \& Chiat (2009) and Ebbels et al. $(2007,2012,2014)$ were RCTs; the others provide a lower level of evidence.

There is also emerging evidence that children with severe, complex and pervasive communication and language disorders (including those associated with autism and learning disabilities) can make progress with direct individualised intervention, usually in combination with collaborative work (discussed further below). Relevant studies tend to focus on the acquisition of specific skills, e.g. requesting using Picture Exchange Communication Scheme (PECS, Bondy and Frost, 1994, not RCT), or precursor skills for language e.g., joint attention (Green et al., 2010). Evidence is also emerging of benefits from direct intervention targeting social communication for children with autism, with outcomes relating to language abilities (Kasari et al., 2012) and parents' ability to respond to their child in a synchronous manner (Green et al., 2010). The National Institute for Health Care and Excellence for children and young people with autism (NICE, 2013) noted suggestive evidence for benefit from direct, early social communication intervention when data from a number of studies were combined (Kendall et al., 2013).

\section{Indirect individualised intervention (Tier 3A)}

Individualised intervention may be delivered indirectly, i.e. planned by an SLT but delivered by others. For pre-school children this is often via parents and for school-aged children via education staff. 
Systematic reviews and meta-analyses of SLT interventions with preschool children (Roberts and Kaiser, 2011, DeVeney et al., 2017, Tosh et al., 2017, Lawler et al., 2013) suggest that parental delivery of individualised intervention can lead to improved speech and language skills for children with expressive language difficulties, including those with intellectual disabilities. Roberts and Kaiser (2011) reported that the majority of studies analysed found larger effect sizes for expressive relative to receptive language and indeed expressive language was the focus of most parent implemented intervention.

Tosh et al. (2017) explored the amount of coaching provided to parents and concluded that home programmes are effective when delivered with high dosage rates and when parents receive direct coaching from an SLT. In addition, they found that across all studies reviewed, effective home programmes had a similar cost to SLT services as direct intervention for comparable gain, with indications that direct intervention provides a more consistent treatment response. Tosh et al. (2017) also caution that the quality of the majority of studies providing evidence of the effectiveness of home programmes is low and thus "the evidence supporting the use of home programs remains poor". For children with language disorder and autism, a systematic review of parent-mediated approaches (Oono et al., 2013) did not find evidence of gains in child-related measures of language, communication or behaviour or reductions in parent stress, but did find evidence of positive change in patterns of parentchild interaction and possibly in receptive vocabulary and severity of autism symptoms.

In educational settings, indirect intervention is usually delivered by education staff or SLT assistants; indeed Tosh et al. (2017) found no studies involving parents with children over 7 years of age. Studies which have demonstrated benefit for children in educational settings (both with pre-schoolers and school-aged children) have involved well-trained and supported staff under the direct management of a research team, SLT or specialist teacher. This applies to interventions aiming to improve joint attention (Lawton and Kasari, 2012) or joint engagement (Wong, 2013) in children with autism; a range of specific speech and language targets in children with speech and/or language disorders (Mecrow et al., 2010), and to expressive language targets for children with expressive (but not receptive) language impairments (Boyle et al., 2009). Boyle et al. (2009) reported minimal treatment effects for children with 
receptive language impairments and/or progress on receptive language targets. In addition, an effectiveness study (McCartney et al., 2011), used the same intervention as that used in Boyle et al. (2009) delivered by school staff, who were provided with the manualised programme, with little ongoing supervision. This study did not result in improved receptive or expressive language. The authors suggest that a likely reason for the differences between the studies was that, in the effectiveness study (McCartney et al., 2011), the intervention was not delivered as intended by the education staff, who were receiving lower levels of support.

\section{Joint collaborative work with parents and/or education staff}

Collaborative work with parents, health and education staff occurs at all tiers: i.e., for the benefit of individual children with identified language disorders (Tier 3), children with language weaknesses (Tier 2), and whole classes of children (Tier 1). Collaborative work is an aspect of SLT services which is not practised universally but which we view as important; hence we consider what this approach may add in this specific section. Collaborative work involves joint planning and decisionmaking about the priorities and method of delivery of an intervention, and is different from training or directing an assistant where the SLT may take on the role of "expert". The aim is often to reduce the functional impact of a child's difficulties on their access to the curriculum, social participation or wellbeing, and to practise new skills in a range of settings (Archibald, 2017).

When parents are working with SLTs on areas of language and communication development, these are likely to be specific to their individual child's needs (i.e., Tier 3). A meta-analysis (Hampton and Kaiser, 2016) showed interventions delivered simultaneously by SLTs and parents to be more effective in improving the spoken language of children with autism than interventions delivered by a clinician or parent only.

Collaborative work between education staff and SLTs may focus on individual children or on whole classes, and systematic reviews (Archibald, 2017, Cirrin et al., 2010) have concluded that collaborative work between SLTs and teachers is beneficial in classes with high numbers of "at-risk" children and also for children with identified language disorders (i.e., across Tiers 1 to 3). 


\section{Training for parents or education staff}

In order to support decision making and the delivery of intervention activities, training for parents and others (particularly education staff) is relevant to all tiers, but needs to be intensive and involve continuing support. At Tier 1 , successful professional development for education staff can range from eight hours (Starling et al., 2012) to more than 50-60 hours (Snow et al., 2014; Markussen-Brown et al., 2017), and effective training is accompanied by individual observation sessions with coaching and/or feedback. Studies of effective Tier 2 interventions involved relatively intensive initial training (four days in Fricke et al., 2013; Bowyer-Crane et al., 2008) followed by on-going training (at least fortnightly), support and monitoring for staff delivering programmes. Larger studies with less training showed smaller effects (Fricke et al., 2017, Thurston et al., 2016). Studies at Tier 3A demonstrating good outcomes for children had high levels of support for parents (Tosh et al., 2017) or involved professionals who were employed and supervised directly by the SLT service or research team (Boyle et al., 2009; Mecrow et al., 2010). In the only study where the level of support provided to staff carrying out Tier $3 \mathrm{~A}$ intervention resembles that provided by current routine SLT services provided in the UK (McCartney et al., 2011), the intervention was not delivered as planned and the children showed little progress. This highlights the need for regular monitoring and support in order to ensure that indirect intervention takes place as intended.

SLTs routinely delegate direct work to others, but the UK Health and Care Professions Council (HCPC) standards of conduct, performance and ethics (2016) state explicitly: "You must only delegate work to someone who has the knowledge, skills and experience needed to carry it out safely and effectively" and "you must continue to provide appropriate supervision and support to those you delegate work to" (page 7). In view of this, it is crucial to establish the levels of training, support, coaching and monitoring required for positive outcomes for children across all tiers of intervention. The evidence cited suggests that limited training offered as a cost-saving substitution for other forms of intervention is unlikely to be effective. Services providing such training need to examine the outcomes for children, in order to establish whether their input has been effective. 


\section{Models of service delivery and intervention}

Based on the evidence summarised above, we have constructed a model of SLT service delivery (Figure 2) presenting possible SLT roles, and a flowchart (Figure 3) showing the key questions which may indicate different pathways to intervention and the intervention an individual child might receive. The answers to these questions indicate the need for an SLT assessment ('red flags' and 'risk factors' predicting on-going problems are discussed below) and the appropriate tier of intervention for a child at a given point in time, which depends on factors shown in Figure 2: relating to poor response to intervention, complexity and severity in terms of both receptive language difficulties and impact of impairment on functioning.

Children

SLT roles in intervention
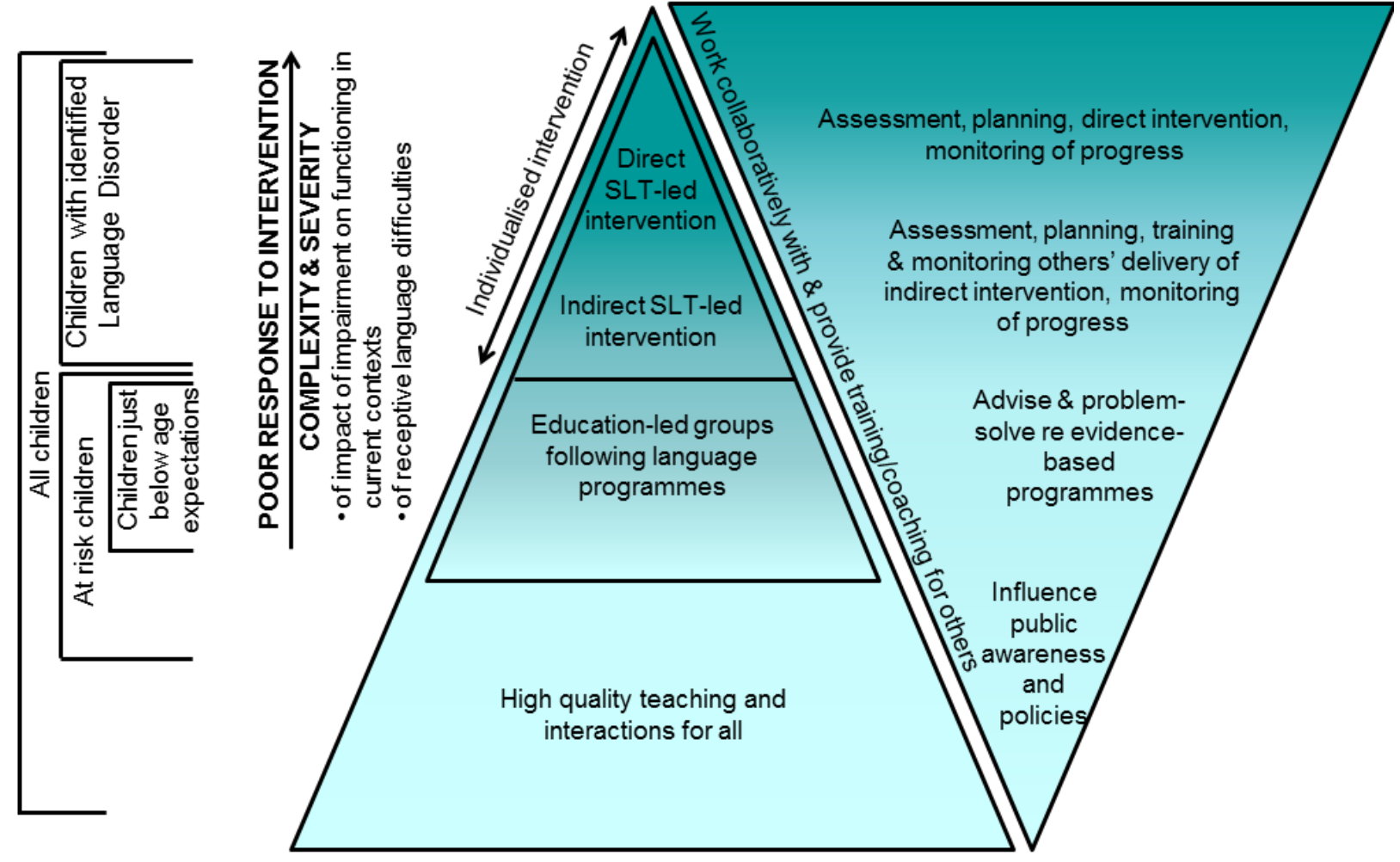

Intervention

Figure 2: SLT roles in response to intervention model of intervention for children with language disorders

Our model in Figure 2 expands on our previous model in Figure 1. Here we have incorporated research evidence to help identify children requiring individualised approaches. We have included 
severity of receptive language difficulties as a core factor in our model because the evidence suggests that these children do not make progress unless provided with direct SLT and/or joint collaborative work. We have added a second triangle on the right which provides examples of possible SLT roles at each tier. Collaborative working and coaching/training cut across all tiers, whereas other SLT roles may be more specific to each tier. Our inversion of the right hand triangle represents firstly the weight of the current evidence base concerning SLT roles in supporting children with language disorders and secondly our view that those children with the greatest needs require the largest proportion of SLT time and specialist skills. This is not to say that children with milder difficulties do not require support, but rather that the specific technical skills of an SLT may not be essential for improving language outcomes for these children (as shown by the success of Tier 1 and Tier 2 studies discussed above which did not involve SLTS). The model is based on current knowledge but, the limited evidence available means it may change if further evidence emerges on treatment outcomes and (cost-)effectiveness of different SLT roles.

\section{Identification of children likely to require individualised intervention at Tier 3}

'Response to Intervention' models have been criticised for creating a "wait to fail" approach (see Reynolds and Shaywitz, 2009), where the impression is that children have to fail at Tiers 1 and 2 before accessing Tier 3. To avoid this, a pathway is needed for children who should see an SLT without delay, including those who are the focus of Bishop et al. (2017), who are likely to have a persisting language disorder. This requires proper evaluation of factors which identify children at risk of a persisting disorder who need individualised intervention from those likely to resolve their language difficulties either spontaneously or with good support at Tiers 1 and 2. This appraisal should take into account the wide variability in child language ability and rate of language development, especially in the pre-school years when early language difficulties are not necessarily predictive of later disorder and some children with language disorder meet early language milestones (Eadie et al., 2014, Zambrana et al., 2014). In these circumstances it is important to consider factors which predict persistent difficulties in order to target scarce resources for early intervention. These can be split into 'red flags' and 'risk factors'. Individual 'red flags' indicate the need for assessment by an SLT without delay; 'risk factors' in 
contrast are associated with language difficulties at a group or population level but do not individually indicate the need for immediate SLT assessment for an individual.

Important 'red flags' in the pre-school period are listed in Bishop et al. (2016) based on those in Visser-Bochane et al. (2017) and are repeated here for ease of reference:

- 1 to 2 years: no babbling, not responding to speech and/or sounds, no interaction;

- 2-3 years: minimal interaction, no display of intention to communicate, no words, minimal reaction to spoken language, regression or stalling of language development;

- 3-4 years: at most two-word utterances (in their first language), child does not understand simple commands, close relatives cannot understand much of child's speech.

Children with any of these red flags should be referred for an SLT assessment. Similar 'red flags' have been suggested for autism spectrum disorder (e.g., Baird et al., 2003).

Longitudinal research has identified additional 'risk factors' which do not individually indicate the need for immediate SLT assessment, but are associated with an increased risk of a persistent language disorder at a group or population level. The most reliable predictor of later language levels is earlier language levels (McKean et al., 2017, 2016, Norbury et al., 2017). Other risk factors identified to date are: a positive family history of language or literacy difficulties (Zambrana et al., 2014); pervasive language deficits affecting both receptive and expressive language, which probably reflect more severe language difficulties (Eadie et al., 2014, Tomblin et al., 2003), particularly in girls (Zambrana et al., 2014); lower non-verbal IQ (e.g., Eadie et al., 2014, Tomblin et al., 2003, McKean et al., 2017); low socioeconomic status (Fisher, 2017). Some risk factors may be identified before a child begins to talk. A metaanalysis of case history risk factors for DLD (Rudolph, 2017) found 11 risk factors were statistically significant predictors of DLD. Of these, the most reliable were: lower maternal education level, lower 5minute Apgar score, later birth order, biological sex, family history and prematurity. These risk factors were as informative as late talker status (but no more) and are all identifiable from the day the child is 
born. However Rudolph (2017) cautions that no single risk factor is by itself a strong predictor of DLD.

Zambrana et al. (2014) identify cumulative risk from multiple risk factors, such that children with low language and multiple risk factors should be considered to be at high risk of persistent language disorder and hence could be fast-tracked for an SLT assessment. There are also a number of clinical markers of DLD and/or social communication difficulties which may also be helpful in identifying children likely to need individualised SLT. For social communication, these include difficulties with social responsiveness, joint attention and symbolic understanding (Roy and Chiat, 2014) and for DLD, difficulties with sentence repetition (Conti-Ramsden et al., 2001) and regular past tense (Conti-Ramsden, 2003, Rice and Wexler, 1996, Werfel et al., 2017). However the status of these remains controversial (Pawłowska, 2014).

Age is also an important factor. Whilst the majority of children with early delays in expressive language will spontaneously improve by school entry (Rescorla, 2011, Paul et al., 2000), language difficulties still evident, or which have emerged, by school entry tend not to resolve (e.g., ContiRamsden et al., 2012). Thus, by 4-5 years, language abilities are much more stable and school-aged children with language difficulties are at high risk of persistent language disorder. In older children and adolescents, language abilities should be checked in those who exhibit behavioural and mental health issues (Hollo et al., 2014).

Language disorders in the context of other developmental conditions such as Down syndrome, or autism are unlikely to resolve spontaneously (Pickles et al., 2014). Intervention for these populations is likely to have a broad remit: establishing communication within the family, perhaps introducing alternative and augmentative communication methods, developing and monitoring oral language, and providing evidence for statutory assessment of education, health and social care plans.

\section{Evidence-based pathways to intervention for children with Language Disorders}

We now bring together the evidence reviewed above into a flowchart (Figure 3), to enable evidence-based decisions regarding the appropriate tier of intervention for an individual child. It includes key decision points, such as whether to refer for an SLT assessment, or to provide direct or indirect SLT intervention. Children can move between tiers based on their response to intervention and 
the functional impact of their difficulties at any given point in time. This model encompasses constant monitoring, including of children who do not appear to have language difficulties when they are young, but whose language difficulties may emerge, or be identified later. Some children have multiple cooccurring difficulties requiring a model of intervention at different tiers simultaneously.

Children with the 'red flags' listed above and those with language difficulties and multiple risk factors should be assessed by an SLT. Children with language difficulties but few additional risk factors may be best served by evidence based Tier 1 and 2 services. For this model to work well, professionals working with children will need training in how to identify language difficulties, 'red flags' and 'risk factors' and how to assess progress in response to Tier 1 and 2 interventions. This should increase the number of appropriate referrals to SLT so that the current high levels of unmet and unrecognised need (Norbury et al., 2016) are reduced.

The primary purpose of Figure 3 is to indicate pathways to intervention, using a response to intervention approach through close monitoring of outcomes and subsequent changes to provision where necessary. Response to intervention could be monitored by education staff for education-led interventions (at Tiers 1 and 2) and by the SLT for interventions where the SLT has a duty of care (at Tiers $3 \mathrm{~A}$ and $3 \mathrm{~B})$. For this to be effective, it is important to define good or poor response to an intervention (Reynolds \& Shaywitz, 2009) particularly for children with complex developmental disorders such as autism (Lord et al., 2005). We would suggest that a child be referred for an SLT assessment if they have not reached expected language levels after Tier 2 intervention. Judgements regarding progress following SLT-led intervention should be made in relation to specific individual targets, rather than broad standardised assessments. Failure to progress should result in a re-evaluation of the intervention and the outcome measures used and, if necessary, modification of the focus, method, or dosage, bearing in mind that children with pervasive difficulties are unlikely to make rapid progress after short-term interventions. 


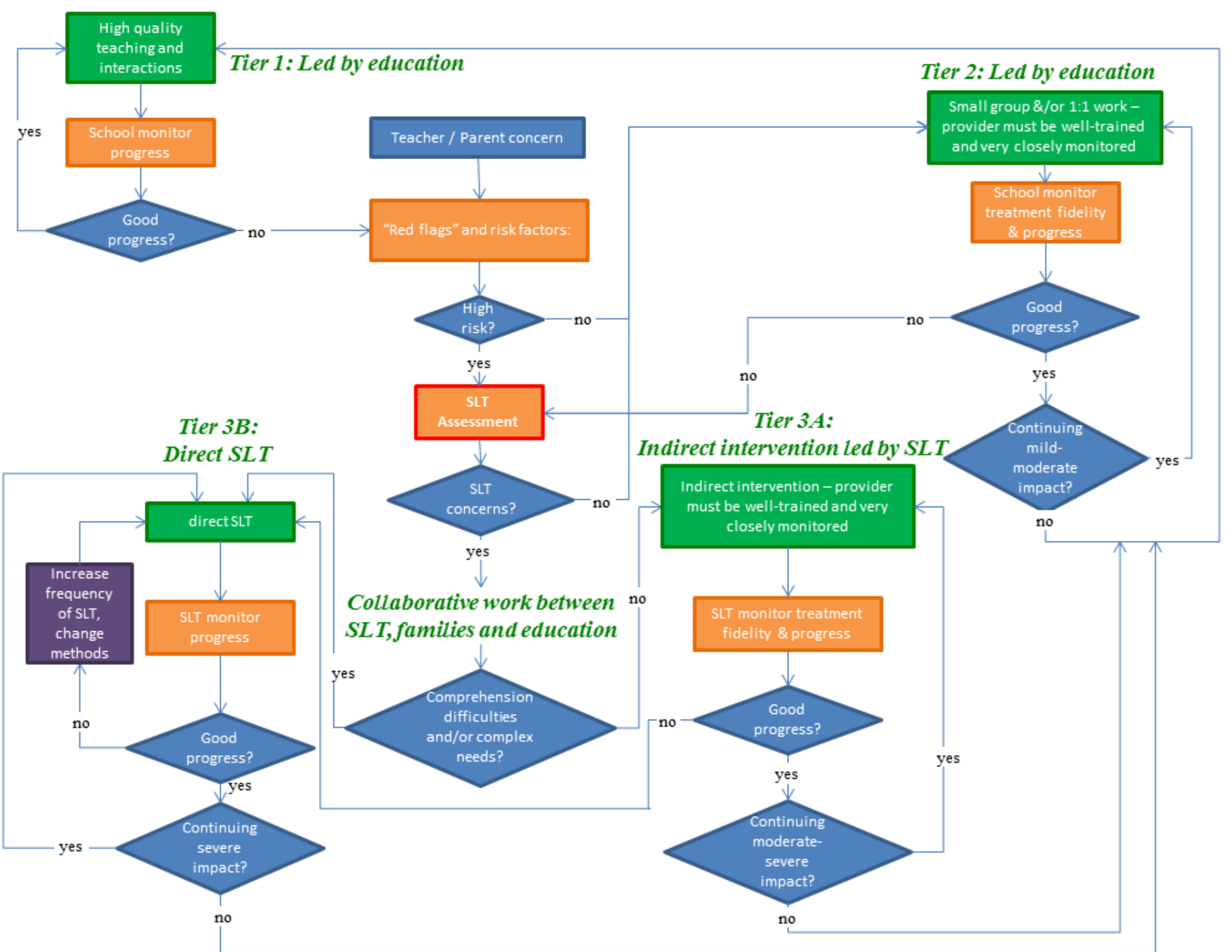

Figure 3: Flowchart of pathways to intervention 


\section{Prioritisation}

Our models in Figures 2 and 3 are based on the evidence we have reviewed. We are uncertain as to the extent to which such information influences managers under pressure to prioritise their service delivery. All health provider services strive to balance the need to reach the maximum number of individuals versus focusing on a smaller number where the impact on the individual could be greatest. An important factor is the degree to which other services provide effective support for a particular group of children and whether SLTs would add a unique and significant component to this. To inform this process it is essential to distinguish between interventions provided by education at Tiers 1 and 2 where, at present, the evidence to support effective SLT-specific roles is limited and those at Tier 3 where the role of the SLT is central.

An associated but different issue is the on-going debate about the prioritisation of younger children, with the aim of preventing potential future difficulties. This concept is primarily used in illness prevention, but its use in SLT services is receiving increased attention (Law et al., 2013). Thus, it has been suggested that Tier 1 services constitute primary prevention of future (language) problems, Tier 2 services aim to reduce the prevalence of (language) difficulties (secondary prevention), while Tier 3 services aim to reduce negative impacts of difficulties (tertiary prevention). It is unclear how "preventable" language difficulties are in terms of primary and secondary prevention. However, the concept of tertiary prevention has utility where the aims are to avoid functional impairments or secondary sequelae (such as poor mental health) and enhance skill development in individuals with long term conditions (including language disorder), even if the condition itself cannot be prevented.

If, as Law et al (2017) point out, a focus on prevention of later difficulties is likely to mean "an element of over-provision will be inevitable" (p56), then the prioritisation of this work by SLTS needs to be questioned. The risk is that Tier 3 SLT services will receive insufficient resource allocation leaving children with severe language disorders (who arguably have the most to gain from the expertise of SLT) without adequate intervention, with potential profound and lifelong consequences. Funding for public health initiatives may support awareness raising, and preventative strategies and education policy has 
provided much at Tier 2 levels of provision. We suggest that SLT services use red flags and risk factors to prioritise individuals likely to have long-term difficulties. This would enable services to provide early and effective intervention to those at highest risk of long-term difficulties whatever their age.

In the context of a health provider, discharge from treatment is often seen as the desired outcome of successful treatment and in the past this may have resulted in SLT services prioritising children whose difficulties are likely to resolve with small amounts of input. This approach is not appropriate for children with neurodevelopmental disorders such as language disorder. It is essential therefore that SLTs are clear about the anticipated outcomes of their work and the means of measuring progress, so that investment of therapy time can be measured against realistic targets. The principles of communication as a human right and an important means of preventing harm (Department of Health, 2012) are relevant here. A key question therefore is how SLT services demonstrate that they can provide high quality intervention for children with severe and complex communication and language disorders which adapts to the changing needs of the individual, their family and society. Service delivery decisions have not been adequately supported by research that includes health economics to indicate cost effectiveness.

\section{Dosage}

Underlying much of the discussion in this paper is the issue of dosage. How much intervention, training, coaching, monitoring, feedback, or joint planning time is required in order for an intervention to be effective? And is this cost-effective? It is clear that adequate dosage depends on many factors, including: 1) the desired outcome or target (i.e. solution focussed for a specified problem or long term skill building); 2) the nature of the child's difficulties and their functional impact; 3) the pre-existing knowledge and skills of the child's family and other professionals working with the child, and 4) the demands of the child's environment. The research literature on dosage is rather limited, but does give examples where inadequate dosage has resulted in a poor outcome: six hours of direct intervention over eight months aimed at improving scores on standardised tests (Glogowska et al., 2000), training for education staff without coaching, feedback or provision of a language programme (Markussen-Brown et 
al., 2017), or provision of targets and materials to those delivering indirect intervention with only one mid-intervention contact with the SLT (McCartney et al., 2011). Such evidence can be useful to service managers and commissioners, but is very limited at present.

Ineffective services benefit no-one and may even cause harm to children who struggle to access the education curriculum and participate socially; to families who lose trust in the professionals providing such services, especially if they have invested time and energy in treatments resulting in opportunity costs, and to professionals who doubt the value of their work, leading to low morale. Thus, the priority must be to provide interventions which are known to have a good chance of being effective, for the benefit of (and to avoid harm to) all involved and to instigate trials to evaluate emerging interventions. Economic evaluations also need to be incorporated into future intervention research so that the cost-effectiveness of interventions is evaluated.

\section{Limitations}

This discussion paper is ambitious in its aims. It was not possible to carry out a systematic review of all relevant papers and policy documents. Instead we drew on systematic or narrative reviews and meta-analyses wherever possible and considered the implications of their combined findings for service delivery. Where high level evidence was not available or was out-dated, we discussed individual papers that illuminated a specific point. We included only group studies with experimental control and statistical analyses. We acknowledge that we may have missed important papers in some areas and that our models may need to change in the light of further evidence. Our discussion is also limited by gaps in the research evidence, particularly around dosage and the value added by different models of service delivery, especially the added value of SLT contributions to Tiers 1 and 2.

\section{Conclusions and points for discussion}

Response to intervention models have been developed to cater for the needs of a wide range of children and all tiers of service delivery are required for the models to work effectively. Our primary focus in this paper is discussion of where SLTs fit into this model for children with language difficulties and disorders. SLTs working in children's services have roles ranging from awareness raising and public 
engagement (Tier 1), to advice, support, training and coaching for parents and professionals working with children at risk of or failing to make expected progress (Tiers 1 to 3), and finally to individualised direct or indirect intervention for children with severe and persisting language disorders (Tier 3). At all tiers, SLTs should be working collaboratively with families, and health and education services, with a particular focus on generalising children's skills and maximising access to the curriculum, social participation and well-being. We highlight the need to incorporate evidence of the effectiveness of these SLT roles in service planning. Our model and flowchart reflect the current evidence and we hope will provide a framework for discussions about service delivery and clinical decisions for intervention for children with language disorders.

Points for discussion include:

1) How can SLTs raise awareness of language disorders (and their impact on children families and society) among professionals, families, policy makers and the general public and how can we measure if we have been effective in this endeavour?

2) How can SLTs improve identification of children with language disorders?

3) How can SLTs best work with professionals who support children with speech, language and communication needs?

4) How can SLTs best support children with language disorders and their families?

5) Given limited resources and the need for cost effective interventions, what factors should influence decisions about prioritisation of SLT services for children and young people?

While discussions may be influenced by political, financial, local, philosophical and ideological perspectives, we hope to promote the consideration of evidence regarding the effectiveness of different approaches to intervention and SLT service delivery models. Ineffective services waste limited resources and time (including the time of SLTs, parents, education staff, and the children themselves) and yet there is evidence that SLTs frequently fail to use evidence-based interventions, preferring to use their own local methods (Roulstone et al., 2012). SLTs should be clear whether and how their services differ from evidence-based interventions and collect data to establish the efficacy of their work. Locally 
gathered data could contribute to national or international evidence to compare effectiveness across

services that have different delivery models, and thus create a resource to help the selection of service delivery models.

The evidence indicates that children with complex and pervasive language disorders and those with additional complex needs require the specialist skills of SLTs at Tier 3 in order to make progress. SLTs need to have adequate time to work directly with these children, and collaboratively with their families and educators, to improve their skills and reduce the functional impact of their language disorder. Thus, we argue that Tier 3 is the core part of our service, while acknowledging that we also have roles supporting schools, pre-schools, families and communities at Tiers 1 and 2, particularly via close, collaborative working relationships with all those who work with and care for children.

\section{References}

APTHORP, H., RANDEL, B., CHERASARO, T., CLARK, T., MCKEOWN, M. \& BECK, I. 2012. Effects of a supplemental vocabulary program on word knowledge and passage comprehension. Journal of Research on Educational Effectiveness, 5, 160-188.

ARCHIBALD, L. M. 2017. SLP-educator classroom collaboration: A review to inform reasonbased practice. Autism \& Developmental Language Impairments, 2, 2396941516680369.

ASMUSSEN, K. A., FEINSTEIN, L., MARTIN, J. \& CHOWDRY, H. 2016. Foundations for Life: What works to support parent-child interaction in the early years. London: The Early Intervention Foundation.

BAIRD, G., CASS, H. \& SLONIMS, V. 2003. Diagnosis of autism. Bmj, 327, 488-493.

BERCOW, J. 2008. The Bercow Report: A review of services for children and young people (0-19) with speech, language and communication needs.

BISHOP, D. V. M., SNOWLING, M. J., THOMPSON, P. A., GREENHALGH, T. \& AND THE, C.-C. 2017. Phase 2 of CATALISE: a multinational and multidisciplinary Delphi consensus study of problems with language development: Terminology. Journal of Child Psychology and Psychiatry, 58, 1068-1080.

BISHOP, D. V. M., SNOWLING, M. J., THOMPSON, P. A., GREENHALGH, T. \& CONSORTIUM, C. 2016. CATALISE: A Multinational and Multidisciplinary Delphi Consensus Study. Identifying Language Impairments in Children. PLoS ONE, 11, e0158753.

BLESES, D., HØJEN, A., JUSTICE, L. M., DALE, P. S., DYBDAL, L., PIASTA, S. B., MARKUSSENBROWN, J., CLAUSEN, M. \& HAGHISH, E. 2017. The Effectiveness of a Large-Scale Language and Preliteracy Intervention: The SPELL Randomized Controlled Trial in Denmark. Child Development.

BONDY, A. S. \& FROST, L. A. 1994. The picture exchange communication system. Focus on autism and other developmental disabilties, 9, 1-19.

BOWYER-CRANE, C., SNOWLING, M. J., DUFF, F. J., FIELDSEND, E., CARROLL, J. M., MILES, J., GOTZ, K. \& HULME, C. 2008. Improving early language and literacy skills: differential 
effects of an oral language versus a phonology with reading intervention. Journal of Child Psychology and Psychiatry, 49, 422-432.

BOYLE, J. M., MCCARTNEY, E., O'HARE, A. \& FORBES, J. 2009. Direct versus indirect and individual versus group modes of language therapy for children with primary language impairment: principal outcomes from a randomized controlled trial and economic evaluation. International Journal of Language \& Communication Disorders, $44,826-846$.

CIRRIN, F. M., SCHOOLING, T. L., NELSON, N. W., DIEHL, S. F., FLYNN, P. F., STASKOWSKI, M., TORREY, T. \& ADAMCZYK, D. F. 2010. Evidence-Based Systematic Review: Effects of Different Service Delivery Models on Communication Outcomes for Elementary School-Age Children. Language Speech and Hearing Services in Schools, 41, 233-264.

CONTI-RAMSDEN, G. 2003. Processing and linguistic markers in young children with specific language impairment (SLI). Journal of Speech Language and Hearing Research, 46, 1029-1037.

CONTI-RAMSDEN, G., BOTTING, N. \& FARAGHER, B. 2001. Psycholinguistic markers for specific language impairment (SLI). Journal of Child Psychology and Psychiatry and Allied Disciplines, 42, 741-748.

CONTI-RAMSDEN, G., ST CLAIR, M. C., PICKLES, A. \& DURKIN, K. 2012. Developmental Trajectories of Verbal and Nonverbal Skills in Individuals With a History of Specific Language Impairment: From Childhood to Adolescence. Journal of Speech Language and Hearing Research, 55, 1716-1735.

COUNCIL, H. A. C. P. 2016. Standards of conduct, performance and ethics. London: Health and Care Professions Council.

DEVENEY, S. L., HAGAMAN, J. L. \& BJORNSEN, A. L. 2017. Parent-Implemented Versus Clinician-Directed Interventions for Late-Talking Toddlers: A Systematic Review of the Literature. Communication Disorders Quarterly, 39, 293-302.

DOCKRELL, J. \& MARSHALL, C. 2015. Measurement issues: Assessing language skills in young children. Child and Adolescent Mental Health, 20, 116-125.

DOCKRELL, J. E., STUART, M. \& KING, D. 2010. Supporting early oral language skills for English language learners in inner city preschool provision. British Journal of Educational Psychology, 80, 497-515.

EADIE, P., NGUYEN, C., CARLIN, J., BAVIN, E., BRETHERTON, L. \& REILLY, S. 2014. Stability of language performance at 4 and 5 years: measurement and participant variability. International Journal of Language \& Communication Disorders, 49, 215-227.

EBBELS, S. H. 2014. Effectiveness of intervention for grammar in school-aged children with primary language impairments: A review of the evidence. Child Language Teaching and Therapy, 30, 7-40.

EBBELS, S. H., MARIC, N., MURPHY, A. \& TURNER, G. 2014. Improving comprehension in adolescents with severe receptive language impairments: a randomised control trial of intervention for coordinating conjunctions. International Journal of Language \& Communication Disorders, 49, 30-48.

EBBELS, S. H., NICOLL, H., CLARK, B., EACHUS, B., GALLAGHER, A. L., HORNIMAN, K., JENNINGS, M., MCEVOY, K., NIMMO, L. \& TURNER, G. 2012. Effectiveness of semantic therapy for word-finding difficulties in pupils with persistent language impairments: a randomized control trial. International Journal of Language \& Communication Disorders, 47, 35-51.

EBBELS, S. H., VAN DER LELY, H. K. J. \& DOCKRELL, J. E. 2007. Intervention for verb argument structure in children with persistent SLI: a randomized control trial. Journal of Speech Language and Hearing Research, 50, 1330-1349.

EBBELS, S. H., WRIGHT, L., BROCKBANK, S., GODFREY, C., HARRIS, C., LENISTON, H., NEARY, K., NICOLL, H., NICOLL, L., SCOTT, J. \& MARIĆ, N. 2017. Effectiveness of 1:1 
speech and language therapy for older children with (developmental) language disorder. International Journal of Language \& Communication Disorders, 52, 528539.

FISHER, E. L. 2017. A Systematic Review and Meta-Analysis of Predictors of ExpressiveLanguage Outcomes Among Late Talkers. Journal of Speech, Language, and Hearing Research, 60, 2935-2948.

FRICKE, S., BOWYER-CRANE, C. A., HALEY, A. J., HULME, C. \& SNOWLING, M. 2013. Efficacy of language intervention in the early years. Journal of Child Psychology and Psychiatry, 54, 280-290.

FRICKE, S., BURGOYNE, K., BOWYER-CRANE, C., KYRIACOU, M., ZOSIMIDOU, A., MAXWELL, L., LERVÅG, A., SNOWLING, M. J. \& HULME, C. 2017. The efficacy of early language intervention in mainstream school settings: a randomized controlled trial. Journal of Child Psychology and Psychiatry, 58, 1141-1151.

FUCHS, D. \& FUCHS, L. S. 2006. Introduction to response to intervention: What, why, and how valid is it? Reading Research Quarterly, 41, 93-99.

GALLAGHER, A. \& CHIAT, S. 2009. Evaluation of speech and language therapy interventions for pre-school children with specific language impairment: a comparison of outcomes following specialist intensive, nursery-based and no intervention. International Journal of Language \& Communication Disorders, 44, 616-638.

GASCOIGNE, M. 2006. Supporting children with speech, language and communication needs within integrated children's services., London, RCSLT Position Paper, RCSLT.

GLOGOWSKA, M., ROULSTONE, S., ENDERBY, P. \& PETERS, T. J. 2000. Randomised controlled trial of community based speech and language therapy in preschool children. British Medical Journal, 321, 923.

GREEN, J., CHARMAN, T., MCCONACHIE, H., ALDRED, C., SLONIMS, V., HOWLIN, P., LE COUTEUR, A., LEADBITTER, K., HUDRY, K., BYFORD, S., BARRETT, B., TEMPLE, K., MACDONALD, W. \& PICKLES, A. 2010. Parent-mediated communication-focused treatment in children with autism (PACT): a randomised controlled trial. The Lancet, 375, 2152-2160.

GRINDAL, T., BOWNE, J. B., YOSHIKAWA, H., SCHINDLER, H. S., DUNCAN, G. J., MAGNUSON, K. \& SHONKOFF, J. P. 2016. The added impact of parenting education in early childhood education programs: A meta-analysis. Children and Youth Services Review, 70, 238-249.

HAMPTON, L. H. \& KAISER, A. P. 2016. Intervention effects on spoken-language outcomes for children with autism: a systematic review and meta-analysis. Journal of Intellectual Disability Research, 60, 444-463.

HEALTH, D. F. E. A. D. 0. 2015. Special educational needs and disability code of practice: 0 to 25 years. Available at: https://www.gov.uk/government/publications/sendcode-of-practice-0-to-25 (Accessed: 29th November 2017).

HEALTH, D. 0. 2012. Winterbourne View Hospital: Department of Health review and response.

HYDE-WRIGHT, S. H., GORRIE, B., HAYNES, C. \& SHIPMAN, A. 1993. What's in a name? Comparative therapy for word-finding difficulties using semantic and phonological approaches. Child Language Teaching and Therapy, 9, 214-229.

KASARI, C., GULSRUD, A., FREEMAN, S., PAPARELLA, T. \& HELLEMANN, G. 2012. Longitudinal Follow Up of Children with Autism Receiving Targeted Interventions on Joint Attention and Play RH = Targeted Interventions on Joint Attention and Play. Journal of the American Academy of Child and Adolescent Psychiatry, 51, 487-495.

KENDALL, T., MEGNIN-VIGGARS, O., GOULD, N., TAYLOR, C., BURT, L. R., BAIRD, G. \& GROUP, G. D. 2013. Management of autism in children and young people: summary of NICE and SCIE guidance. Bmj, 347, f4865. 
LANDRY, S. H., SMITH, K. E. \& SWANK, P. R. 2006. Responsive parenting: establishing early foundations for social, communication, and independent problem-solving skills. Developmental psychology, 42, 627.

LAW, J., CHARLTON, J., DOCKRELL, J., GASCOIGNE, M., MCKEAN, C. \& THEAKSTON, A. 2017. Early Language Development: Needs, provision, and intervention for preschool children from socioeconomically disadvantaged backgrounds. A Report for the Education Endowment Foundation. October 2017.: The Education Endowment Foundation.

LAW, J., GARRETT, Z. \& NYE, N. 2003. Speech and Language Therapy Interventions for Children with Primary Speech and Language Delay or Disorder (Cochrane Review). Cochrane Database of Systematic Reviews, Issue 3, Art.No: CD004110. DOI: $10.1002 / 14651858$.

LAW, J., LEE, W., ROULSTONE, S., WREN, Y., ZENG, B. \& LINDSAY, G. 2012. What works : Interventions for children with speech language and communication needs, Nottingham, DfE.

LAW, J. \& PAGNAMENTA, E. 2017. Public Health Interventions: Promoting the development of young children's language. Bulletin of the Royal College of Speech and Language Therapists.

LAW, J., REILLY, S. \& SNOW, P. C. 2013. Child speech, language and communication need reexamined in a public health context: a new direction for the speech and language therapy profession. International Journal of Language \& Communication Disorders, 48, 486-496.

LAWLER, K., TAYLOR, N. F. \& SHIELDS, N. 2013. Outcomes After Caregiver-Provided Speech and Language or Other Allied Health Therapy: A Systematic Review. Archives of Physical Medicine and Rehabilitation, 94, 1139-1160.

LAWTON, K. \& KASARI, C. 2012. Teacher-implemented joint attention intervention: Pilot randomized controlled study for preschoolers with autism. Journal of consulting and clinical psychology, 80, 687.

LEE, W. \& PRING, T. 2016. Supporting language in schools: Evaluating an intervention for children with delayed language in the early school years. Child Language Teaching and Therapy, 32, 135-146.

LINDSAY, G., RICKETTS, J., PEACEY, L. V., DOCKRELL, J. E. \& CHARMAN, T. 2016. Meeting the educational and social needs of children with language impairment or autism spectrum disorder: the parents' perspectives. International Journal of Language \& Communication Disorders, 51, 495-507.

LONIGAN, C. J. \& PHILLIPS, B. M. 2016. Response to instruction in preschool: Results of two randomized studies with children at significant risk of reading difficulties. Journal of educational psychology, 108, 114.

LORD, C., WAGNER, A., ROGERS, S., SZATMARI, P., AMAN, M., CHARMAN, T., DAWSON, G., DURAND, V. M., GROSSMAN, L., GUTHRIE, D., HARRIS, S., KASARI, C., MARCUS, L., MURPHY, S., ODOM, S., PICKLES, A., SCAHILL, L., SHAW, E., SIEGEL, B., SIGMAN, M., STONE, W., SMITH, T. \& YODER, P. 2005. Challenges in Evaluating Psychosocial Interventions for Autistic Spectrum Disorders. Journal of Autism and Developmental Disorders, 35, 695-708.

LOWE, H., HENRY, L., MÜLLER, L.-M. \& JOFFE, V. L. in press. Vocabulary intervention for adolescents with language disorder: a systematic review. International Journal of Language \& Communication Disorders, n/a-n/a.

MANZ, P. H., HUGHES, C., BARNABAS, E., BRACALIELLO, C. \& GINSBURG-BLOCK, M. 2010. A descriptive review and meta-analysis of family-based emergent literacy interventions: To what extent is the research applicable to low-income, ethnic- 
minority or linguistically-diverse young children? Early Childhood Research Quarterly, 25, 409-431.

MARKUSSEN-BROWN, J., JUHL, C. B., PIASTA, S. B., BLESES, D., HØJEN, A. \& JUSTICE, L. M. 2017. The effects of language-and literacy-focused professional development on early educators and children: A best-evidence meta-analysis. Early Childhood Research Quarterly, 38, 97-115.

MARULIS, L. M. \& NEUMAN, S. B. 2013. How Vocabulary Interventions Affect Young Children at Risk: A Meta-Analytic Review. Journal of Research on Educational Effectiveness, 6, 223-262.

MCCARTNEY, E., BOYLE, J., ELLIS, S., BANNATYNE, S. \& TURNBULL, M. 2011. Indirect language therapy for children with persistent language impairment in mainstream primary schools: outcomes from a cohort intervention. International Journal of Language \& Communication Disorders, 46, 74-82.

MCGILLION, M., PINE, J. M., HERBERT, J. S. \& MATTHEWS, D. 2017. A randomised controlled trial to test the effect of promoting caregiver contingent talk on language development in infants from diverse socioeconomic status backgrounds. Journal of Child Psychology and Psychiatry, 58, 1122-1131.

MCKEAN, C., LAW, J., MENSAH, F., CINI, E., EADIE, P., FRAZER, K. \& REILLY, S. 2016. Predicting Meaningful Differences in School-Entry Language Skills from Child and Family Factors Measured at 12 months of Age. International Journal of Early Childhood, 48, 329-351.

MCKEAN, C., REILLY, S., BAVIN, E. L., BRETHERTON, L., CINI, E., CONWAY, L., COOK, F., EADIE, P., PRIOR, M., WAKE, M. \& MENSAH, F. 2017. Language Outcomes at 7 Years: Early Predictors and Co-Occurring Difficulties. Pediatrics.

MCLEOD, S. 2018. Communication rights: Fundamental human rights for all. International Journal of Speech-Language Pathology, 20, 3-11.

MECROW, C., BECKWITH, J. \& KLEE, T. 2010. An exploratory trial of the effectiveness of an enhanced consultative approach to delivering speech and language intervention in schools. International Journal of Language \& Communication Disorders, 45, 354-367.

MOL, S. E., BUS, A. G., DE JONG, M. T. \& SMEETS, D. J. H. 2008. Added Value of Dialogic Parent-Child Book Readings: A Meta-Analysis. Early Education and Development, 19, 7-26.

NEUMAN, S. B., NEWMAN, E. H. \& DWYER, J. 2011. Educational Effects of a Vocabulary Intervention on Preschoolers' Word Knowledge and Conceptual Development: A Cluster-Randomized Trial. Reading Research Quarterly, 46, 249-272.

NICE, N. I. F. H. A. C. E. 2013. Autism spectrum disorder in under 19s: support and management. London: NICE.

NORBURY, C. F., VAMVAKAS, G., GOOCH, D., BAIRD, G., CHARMAN, T., SIMONOFF, E. \& PICKLES, A. 2017. Language growth in children with heterogeneous language disorders: a population study. Journal of Child Psychology and Psychiatry, 58, 10921105.

OONO, I. P., HONEY, E. J. \& MCCONACHIE, H. 2013. Parent-mediated early intervention for young children with autism spectrum disorders (ASD). Evidence-Based Child Health: A Cochrane Review Journal, 8, 2380-2479.

PAUL, R., BISHOP, D. \& LEONARD, L. 2000. Predicting outcomes of early expressive language delay: Ethical implications. Speech and language impairments in children: Causes, characteristics, intervention and outcome, 195-209.

PAWŁOWSKA, M. 2014. Evaluation of Three Proposed Markers for Language Impairment in English: A Meta-Analysis of Diagnostic Accuracy Studies. Journal of Speech, Language, and Hearing Research, 57, 2261-2273. 
PICKLES, A., ANDERSON, D. K. \& LORD, C. 2014. Heterogeneity and plasticity in the development of language: a 17-year follow-up of children referred early for possible autism. Journal of Child Psychology and Psychiatry, 55, 1354-1362.

PRING, T., FLOOD, E., DODD, B. \& JOFFE, V. 2012. The working practices and clinical experiences of paediatric speech and language therapists: a national UK survey. International Journal of Language \& Communication Disorders, 47, 696-708.

RCSLT 2017. RCSLT briefing paper on Language Disorder with a specific focus on Developmental Language Disorder. London: RCSLT.

RESCORLA, L. 2011. Late talkers: do good predictors of outcome exist? Developmental Disabilities Research Reviews, 17, 141-150.

REYNOLDS, C. R. \& SHAYWITZ, S. E. 2009. Response to Intervention: Ready or not? Or, from wait-to-fail to watch-them-fail. School Psychology Quarterly, 24, 130.

RICE, M. L. \& WEXLER, K. 1996. Toward tense as a clinical marker of specific language impairment in English-speaking children. Journal of Speech and Hearing Research, $39,1239-1257$.

ROBERTS, M. Y. \& KAISER, A. P. 2011. The Effectiveness of Parent-Implemented Language Interventions: A Meta-Analysis. American Journal of Speech-Language Pathology, 20, 180-199.

ROULSTONE, S., WREN, Y., BAKOPOULOU, I., GOODLAD, S. \& LINDSAY, G. L. 2012. Exploring interventions for children and young people with speech, language and communication needs: A study of practice. In: DFE (ed.). London.

ROY, P. \& CHIAT, S. 2014. Developmental pathways of language and social communication problems in 9-11 year olds: Unpicking the heterogeneity. Research in developmental disabilities, 35, 2534-2546.

RUDOLPH, J. M. 2017. Case History Risk Factors for Specific Language Impairment: A Systematic Review and Meta-Analysis. American Journal of Speech-Language Pathology, 26, 991-1010.

SCOTTISH_GOVERNMENT 2010. Guidance on Partnership Working between Allied Health Professions and Education, http://www.gov.scot/Resource/Doc/313416/0099357.pdf.

SMITH, C., WILLIAMS, E. \& BRYAN, K. 2017. A systematic scoping review of speech and language therapists' public health practice for early language development. International Journal of Language \& Communication Disorders, 52, 407-425.

SNOW, P. C., EADIE, P. A., CONNELL, J., DALHEIM, B., MCCUSKER, H. J. \& MUNRO, J. K. 2014. Oral language supports early literacy: A pilot cluster randomized trial in disadvantaged schools. International Journal of Speech-Language Pathology, 16, 495506.

SNOW, P. C., SANGER, D. D., CAIRE, L. M., EADIE, P. A. \& DINSLAGE, T. 2015. Improving communication outcomes for young offenders: a proposed response to intervention framework. International Journal of Language \& Communication Disorders, 50, 1-13.

STARLING, J., MUNRO, N., TOGHER, L. \& ARCIULI, J. 2012. Training secondary school teachers in instructional language modification techniques to support adolescents with language impairment: a randomized controlled trial. Language, speech, and hearing services in schools, 43, 474-495.

THRONEBURG, R. N., CALVERT, L. K., STURM, J. J., PARAMBOUKAS, A. A. \& PAUL, P. J. 2000. A comparison of service delivery models: effects on curricular vocabulary skills in the school setting. American Journal of Speech-Language Pathology, 9, 10-20.

THURSTON, A., ROSETH, C., O'HARE, L., DAVISON, J. \& STARK, P. 2016. Talk of the Town. Evaluation report and executive summary. Education Endowment Foundation. 
TOMBLIN, J. B., ZHANG, X., BUCKWALTER, P. \& O'BRIEN, M. 2003. The stability of primary language disorder: Four years after kindergarten diagnosis. Journal of Speech Language and Hearing Research, 46, 1283-1296.

TOSH, R., ARNOTT, W. \& SCARINCI, N. 2017. Parent-implemented home therapy programmes for speech and language: a systematic review. International Journal of Language \& Communication Disorders, 52, 253-269.

VADASY, P. F., SANDERS, E. A. \& LOGAN HERRERA, B. 2015. Efficacy of Rich Vocabulary Instruction in Fourth-and Fifth-Grade Classrooms. Journal of Research on Educational Effectiveness, 8, 325-365.

VISSER-BOCHANE, M. I., GERRITS, E., VAN DER SCHANS, C. P., REIJNEVELD, S. A. \& LUINGE, M. R. 2017. Atypical speech and language development: a consensus study on clinical signs in the Netherlands. International Journal of Language \& Communication Disorders, 52, 10-20.

WALES, D., SKINNER, L. \& HAYMAN, M. 2017. The Efficacy of Telehealth-Delivered Speech and Language Intervention for Primary School-Age Children: A Systematic Review. $2017,16$.

WERFEL, K. L., HENDRICKS, A. E. \& SCHUELE, C. M. 2017. The Potential of Past Tense Marking in Oral Reading as a Clinical Marker of Specific Language Impairment in School-Age Children. Journal of Speech, Language, and Hearing Research, 60, 35613572.

WONG, C. S. 2013. A play and joint attention intervention for teachers of young children with autism: A randomized controlled pilot study. Autism, 17, 340-357.

WRIGHT, L., PRING, T. \& EBBELS, S. H. in press. Effectiveness of vocabulary intervention for older children with Developmental Language Disorder (DLD). International Journal of Language \& Communication Disorders.

ZAMBRANA, I. M., PONS, F., EADIE, P. \& YSTROM, E. 2014. Trajectories of language delay from age 3 to 5: persistence, recovery and late onset. International Journal of Language \& Communication Disorders, 49, 304-316. 